\title{
Assessment of Anxiety and Depression in Patients with Acne Vulgaris in Medina: A Case-Control Study
}

\author{
Amr Molla $\mathbb{D}^{\prime}$ \\ Hassan Alrizqi ${ }^{2}$ \\ Emtinan Alharbi $\mathbb{I D}^{2}$ \\ Arwa Alsubhi ${ }^{3}$ \\ Saad Alrizqi ${ }^{4}$ \\ Omar Shahada ${ }^{4}$ \\ 'Department of Medicine, Taibah \\ University, Medina, Saudi Arabia; ${ }^{2}$ Medina \\ Specialist Hospital, Medina, Saudi Arabia; \\ ${ }^{3}$ Department of Dermatology, King Saud \\ Medical City, Riyadh, Saudi Arabia; \\ ${ }^{4}$ College of Medicine, Taibah University, \\ Medina, Saudi Arabia
}

Purpose: Acne vulgaris is a common dermatological disease in adolescents that show high prevalence rates of anxiety and depression that may lead to consequences that affect quality of life. This study aimed to assess and compare anxiety and depression in patients with acne and a control group and to determine their correlation with other demographic data.

Patients and Methods: This was a case-control study conducted in 2019 for 3 months at the derma-tology department of Ohud Hospital and two other private clinics in the Medina region of Saudi Arabia. For this study, 296 consecutive patients in the age group of 12 to 60 years who were diagnosed as having acne vulgaris were enrolled and matched with a control group. Data were collected through a self-administered questionnaire, including sociodemographic data and Hospital Anxiety and Depression Scale scores.

Results: We found no significant differences between the two groups regarding sex, age group, nationality, and educational level, but found a significant difference in marital status $(\mathrm{p}<0.001)$. Most $(62.5 \%)$ of the acne cases were moderate in severity. The overall anxiety score in the acne group was $7.68 \pm 4.90$, with a significant difference with the control group $(p=0.031)$, whereas the anxiety level and depression score showed no significant difference $(\mathrm{p}=0.082$ and $\mathrm{p}=0.656$, respectively). Moreover, a strong correlation was found between anxiety and depression in the acne group $(\mathrm{r}=0.732, \mathrm{p}<0.001)$.

Conclusion: A positive correlation was found between the anxiety and depression scores in the patients with acne, which was not related to age group or educational level. However, the anxiety scores of the patients with acne showed a significant relationship with sex.

Keywords: GAGS, HADS questionnaire, anxiety, depression, acne vulgaris, case control

\section{Introduction}

Acne vulgaris is a long-term dermatological disease characterized by formation of comedones, reddish papules, and cyst with or without scarring due to inflammation of the pilosebaceous unit. It is common during the adolescence period and in young adults, between the 15- and 25-year age group, with a prevalence reaching up to $85 \%$ in adolescents. It mainly presents in the face but can also occur in the back, deltoid region, and upper trunk. ${ }^{1,2}$ Post-adolescent acne has two distinct subtypes, persistent acne, which begins at adolescence and persists till adulthood, and late-onset acne, which starts after the age of 25 years. $^{3}$ Acne confers a significant psychological burden, as it is commonly present in the face, denoted by the dissatisfaction with the perception of body image and facial attractiveness. ${ }^{4}$ This is explained by the face being a powerful tool for social communication between humans, as it devotes visual attention. ${ }^{5}$
Correspondence: Amr Molla Department of Medicine, College of Medicine, Taibah University, 344

Universities Road, Medina, 42353, Saudi Arabia

Tel +966504342992

Email amolla@taibahu.edu.sa 
The prevalence of all anxiety disorders in Saudi Arabia determined a through community survey is $13.2 \%$, and other data showed a high prevalence of anxiety among college students. ${ }^{6}$ Anxiety and depressive symptoms were more prevalent among patients with dermatological disease $\left(39.5 \%\right.$ in psoriasis and $30.2 \%$ in acne). ${ }^{7}$

Many studies showed high prevalence rates of depression and anxiety among patients with acne, reaching up to $>40 \%$, with suicidal cases in $6-7 \%$. This is due to the increase in psychiatric comorbidities in chronic diseases. ${ }^{4}$ A systematic review that included 42 studies revealed high prevalence rates of depression and anxiety among patients with acne as compared with controls $(\mathrm{p}<0.0001)$, and showed a high association of acne with depression and anxiety among adults. ${ }^{8}$

Acne has lifelong psychological effects such as decreasing self-esteem, impaired self-image, dissatisfaction with facial appearance, and problematic social relations. ${ }^{9}$ For this reason, long-term management of acne, including assessment of psychometric outcomes, is the most effective treatment of acne vulgaris and can improve self-confidence and self-esteem. ${ }^{10}$

\section{Materials and Methods}

This was a case-control study conducted for a duration of 3 months between October and December 2019 at the dermatology department of Ohud Hospital and two other private clinics in the Medina region of Saudi Arabia. Two hundred ninety-six consecutive patients in the age group of 12 to 60 years who were diagnosed as having acne vulgaris were included. Patients with chronic medical illnesses, past history of psychiatric disorders, other dermatological diseases, pregnancy, lactation, mental retardation, use of drugs that can exacerbate acne, and steroid-induced acne were excluded from the study. Two hundred ninety-six sex- and age-matched controls were also enrolled. The subjects in the control group were selected from among the relatives of the patients or the hospital employees with similar sociodemographic characteristics and no history of acne vulgaris and medical illness.

\section{Data Collection}

The data collection tool consisted of a self-administered questionnaire, including sociodemographic data and the Hospital Anxiety and Depression Scale (HADS), which was administered to the patients and matched controls. Acne was assessed and graded by a dermatologist, using the global acne grading system (GAGS). Anxiety and depression were evaluated using the validated Arabic version of the HADS.

\section{Acne Grading}

The participants were examined for acne grade by a dermatologist, using the GAGS developed by Doshi and colleagues in 1997, which assesses acne severity through an evaluation of the essential clinical components of primary acne lesions and facial and extra-facial sites of involvement by dividing the face, chest, and upper back into six anatomical areas. Each anatomical area, including the forehead, right cheek, left cheek, nose, chin, and chest and upper back combined, is represented by a given factor of 2, 2, 2, 1, 1, and 3, respectively, based on the surface area, distribution, and density of the pilosebaceous units. Each acne lesion is scored into a scale ranging from 0 to 4 points depending on the clinical description of the lesion (comedones, 1; papules, 2; pustules, 3; and nodules, 4). An anatomical area devoid of an acne lesion is given zero points. The local score for each anatomical area is generated by multiplying the given factor by the points of the most severe lesion within an area. The local scores are summed to obtain the total GAGS score, which categorizes acne severity into no acne ( 0 points), mild acne (1-18), moderate acne (19-30), severe acne (31-38), and very severe acne $(\geq 39) .{ }^{11}$

\section{Hospital Anxiety and Depression Scale}

The HADS was created originally by Zigmond and Snaith in $1983 .{ }^{12}$ It is a valid self-assessment instrument used to evaluate the psychological status of non-psychiatric patients without addressing the somatic symptoms in the setting of outpatient clinics. It constitutes of the anxiety subscale (HADS-A) and depression subscale (HADS-D). The HADS instrument contains 14 items (seven items for each subscale). Four response options are available for each item, which are scored with values ranging from 0 to 3 , with three indicating the highest anxiety or depression level. The scores of the individual items are added to generate a total score ranging from 0 to 21 for each subscale. A total HADS-A or HADS-D score $\geq 8$ of 21 points is consistent with the presence of symptoms of anxiety or depression. ${ }^{12}$ The reliability and validity of the Arabic version of the HADS, which was used in this study, was demonstrated by Terkawi et al. ${ }^{13}$ 
Table I Description of Sociodemographic Characteristics According to the Patients with Acne Vulgaris

\begin{tabular}{|c|c|c|c|c|}
\hline \multirow[t]{2}{*}{ Study Data } & \multirow[t]{2}{*}{ Overall n (\%) (n=592) } & \multicolumn{2}{|l|}{ Acne Vulgaris } & \multirow[b]{2}{*}{ P-value } \\
\hline & & Case $n(\%)(n=296)$ & Control n (\%) $(n=296)$ & \\
\hline $\begin{array}{l}\text { Sex } \\
\text { - Male } \\
\text { - Female }\end{array}$ & $\begin{array}{l}192(32.4 \%) \\
400(67.6 \%)\end{array}$ & $\begin{array}{l}96(32.4 \%) \\
200(67.6 \%)\end{array}$ & $\begin{array}{l}96(32.4 \%) \\
200(67.6 \%)\end{array}$ & 1.000 \\
\hline $\begin{array}{l}\text { Age group } \\
\begin{array}{l}\text { - } 12-22 \text { years } \\
\text { - } 23-33 \text { years } \\
\text { - } 34-60 \text { years }\end{array}\end{array}$ & $\begin{array}{l}220(37.2 \%) \\
253(42.7 \%) \\
119(20.1 \%)\end{array}$ & $\begin{array}{l}110(37.2 \%) \\
127(42.9 \%) \\
59(19.9 \%)\end{array}$ & $\begin{array}{l}\text { III (37.5\%) } \\
125(42.2 \%) \\
60(20.3 \%)\end{array}$ & 0.986 \\
\hline $\begin{array}{l}\text { Nationality } \\
\text { - Saudi } \\
\text { - Non-Saudi }\end{array}$ & $\begin{array}{l}564(95.3 \%) \\
28(04.7 \%)\end{array}$ & $\begin{array}{l}285(96.3 \%) \\
11(03.7 \%)\end{array}$ & $\begin{array}{l}279 \text { (94.3\%) } \\
17(05.7 \%)\end{array}$ & 0.245 \\
\hline $\begin{array}{l}\text { Marital status } \\
\text { - Never married } \\
\text { - Married }\end{array}$ & $\begin{array}{l}374(63.2 \%) \\
218(36.8 \%)\end{array}$ & $\begin{array}{l}211 \text { (71.3\%) } \\
85 \text { (28.7\%) }\end{array}$ & $\begin{array}{l}163(55.1 \%) \\
133(44.9 \%)\end{array}$ & $<0.001 * *$ \\
\hline $\begin{array}{l}\text { Educational level } \\
\text { - High school or lower } \\
\text { - Bachelor's degree }\end{array}$ & $\begin{array}{l}160(27.0 \%) \\
432(73.0 \%)\end{array}$ & $\begin{array}{l}89(30.1 \%) \\
207(69.9 \%)\end{array}$ & $\begin{array}{l}71(24.0 \%) \\
225(76.0 \%)\end{array}$ & 0.096 \\
\hline
\end{tabular}

Notes: The $p$ values were calculated using the chi-square test. **Significant at $p<0.05$.

\section{Ethical Consideration}

Written informed consent was obtained from the patients and controls. Consent was obtained from the parents of the patients who were aged $<18$ years. The participants were ensured about the confidentiality of their data. This study was approved by the ethical committee of Taibah University (006-1441) and conducted in accordance with the Declaration of Helsinki.

\section{Statistical Analyses}

Data analyses were performed using SPSS version 21 (IBM Corp., Chicago, IL, USA). Descriptive statistics were presented using mean and standard deviation, or count and proportion (\%), whichever are appropriate. The relationships between the sociodemographic characteristics and the levels of anxiety and depression were assessed using the chi-square test, while acne severity was compared between the anxiety and depression scores using the Kruskal-Wallis test (nonparametric test). The correlation procedure was performed using the Pearson correlation analysis. A P value $<0.05$ was considered statistically significant. The normality of data was also assessed using the Shapiro-Wilk test.

\section{Results}

Of the 592 participants, 296 with acne vulgaris (case group) and 296 without acne vulgaris (control group) were enrolled. Table 1 presents the sociodemographic characteristics of the participants. The proportion of females was predominantly higher than that of males $(67.6 \%$ vs $32.4 \%)$. The most common age group was 23-33 years $(42.7 \%)$, and nearly all the participants were Saudis (95.3\%). Furthermore, nearly two-thirds (63.2\%) of the participants had never been married. With respect to their education, most attained a bachelor's degree (73\%). In the comparison of the patients with and those without acne vulgaris, we found that the prevalence of acne was statistically significantly higher among the patients who were single $(\mathrm{p}<0.001)$. The other sociodemographic characteristics of the respondents did not show a significant relationship with the presence of acne vulgaris $(p>0.05)$.

Regarding the severity of acne, most patients were diagnosed as having moderate acne $(62.5 \%)$, followed by mild and severe acne (both 18\%; Figure 1).

The prevalence rates of anxiety and depression according to the HADS scores are shown in Table 2. On the basis of these results, the overall mean $( \pm \mathrm{SD})$ anxiety score was $7.26 \pm 4.69$, with approximately $44 \%$ of the participants having anxiety, whereas $56.3 \%$ had no anxiety. With regard to depression, the mean $( \pm \mathrm{SD})$ depression score was $7.44 \pm 4.14$, with more than a half $(51 \%)$ of the participants having no depression, whereas $49.0 \%$ had 


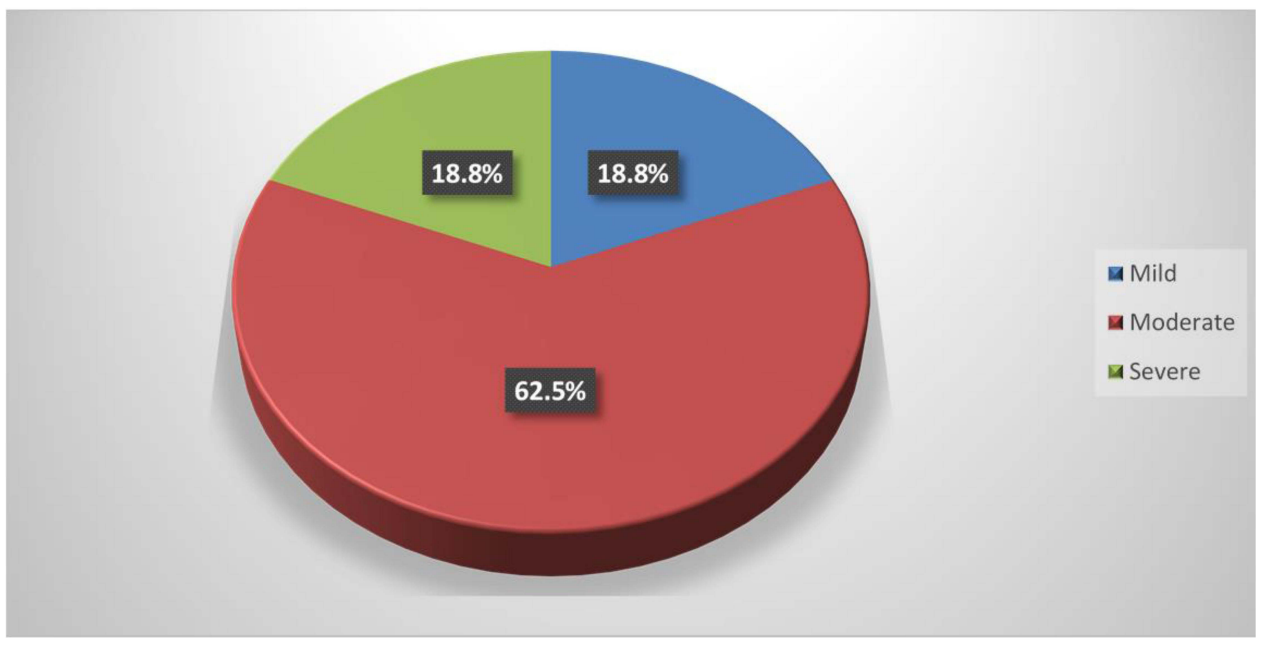

Figure I Shows the severity of acne vulgaris among the cases.

depression. Statistical analysis revealed that the anxiety scores of the patients with acne were statistically significantly higher than those of the participants without acne (p $=0.031)$. On the contrary, the depression score and level did not show any significant relationship when compared with those of the patients with acne vulgaris $(p>0.05)$.

In Figure 2, the Pearson correlation analysis was used to measure the line agreement between the anxiety and depression scores. The correlation was highly positively significant $(r=0.732, p<0.001)$, which suggests that while anxiety increased, depression also likely increased.

When measuring the association with anxiety level between the two study groups, we found that in the case group, the female participants were significantly anxious ( $\mathrm{p}=0.019$ ), and anxiety was more prevalent on the younger age group (40.7\%), Saudis (97.9\%), never-married participants (70\%), and those with a bachelor's degree (74.3\%). However, this did not differ significantly among the groups. On the other hand, the differences in anxiety level and sociodemographic characteristics were not statistically significant between the case and control groups (Table 3).

In regard to the association between depression level and the sociodemographic characteristics of the study participants with and those without acne vulgaris, no significant differences in sex, nationality, and marital status were found, whereas in the control group, the proportion of those with a bachelor's degree who had depression was significantly higher $(\mathrm{p}=0.014$; Table 4$)$.

In Table 5, there was no significant relationship between acne severity and the anxiety and depression scores of the patients with acne vulgaris $(\mathrm{p}=0.138$ and $\mathrm{p}=0.175$, respectively).

\section{Discussion}

Many studies have shown that dermatological disorders such as acne, eczema, and psoriasis affect the psychological status

Table 2 Prevalence of Anxiety and Depression (HADS Score) Among the Patients with Acne Vulgaris

\begin{tabular}{|c|c|c|c|c|}
\hline HADS Parameters & Overall $n(\%)(n=592)$ & Case $n(\%)(n=296)$ & Control $n(\%)(n=296)$ & P-value \\
\hline Anxiety score $(\text { mean } \pm S D)^{a}$ & $7.26 \pm 4.69$ & $7.68 \pm 4.90$ & $6.85 \pm 4.44$ & $0.031 * *$ \\
\hline $\begin{array}{l}\text { Level of anxiety } \\
\text { - Not anxious }(<8) \\
\text { - Anxious }(\geq 8)\end{array}$ & $\begin{array}{l}333(56.3 \%) \\
259(43.8 \%)\end{array}$ & $\begin{array}{l}156(52.7 \%) \\
140(47.3 \%)\end{array}$ & $\begin{array}{l}177 \text { (59.8\%) } \\
119 \text { (40.2\%) }\end{array}$ & 0.082 \\
\hline Depression score $(\text { mean } \pm S D)^{a}$ & $7.44 \pm 4.14$ & $7.52 \pm 4.22$ & $7.37 \pm 4.07$ & 0.656 \\
\hline $\begin{array}{l}\text { Level of depression }{ }^{\mathrm{b}} \\
\text { - Not depressed }(<8) \\
\text { - Depressed }(\geq 8)\end{array}$ & $\begin{array}{l}302(51.0 \%) \\
290(49.0 \%)\end{array}$ & $\begin{array}{l}\text { I } 44 \text { (48.6\%) } \\
\text { I52 (5I.4\%) }\end{array}$ & $\begin{array}{l}\text { I } 46 \text { (49.3\%) } \\
\text { I } 50(50.7 \%)\end{array}$ & 0.869 \\
\hline
\end{tabular}

Notes: ${ }^{a}$-value calculated using the independent $t$ test. ${ }^{b} \mathrm{P}$-value calculated using the chi-square test. ${ }^{* *}$ Significant at $\mathrm{P}<0.05$ 


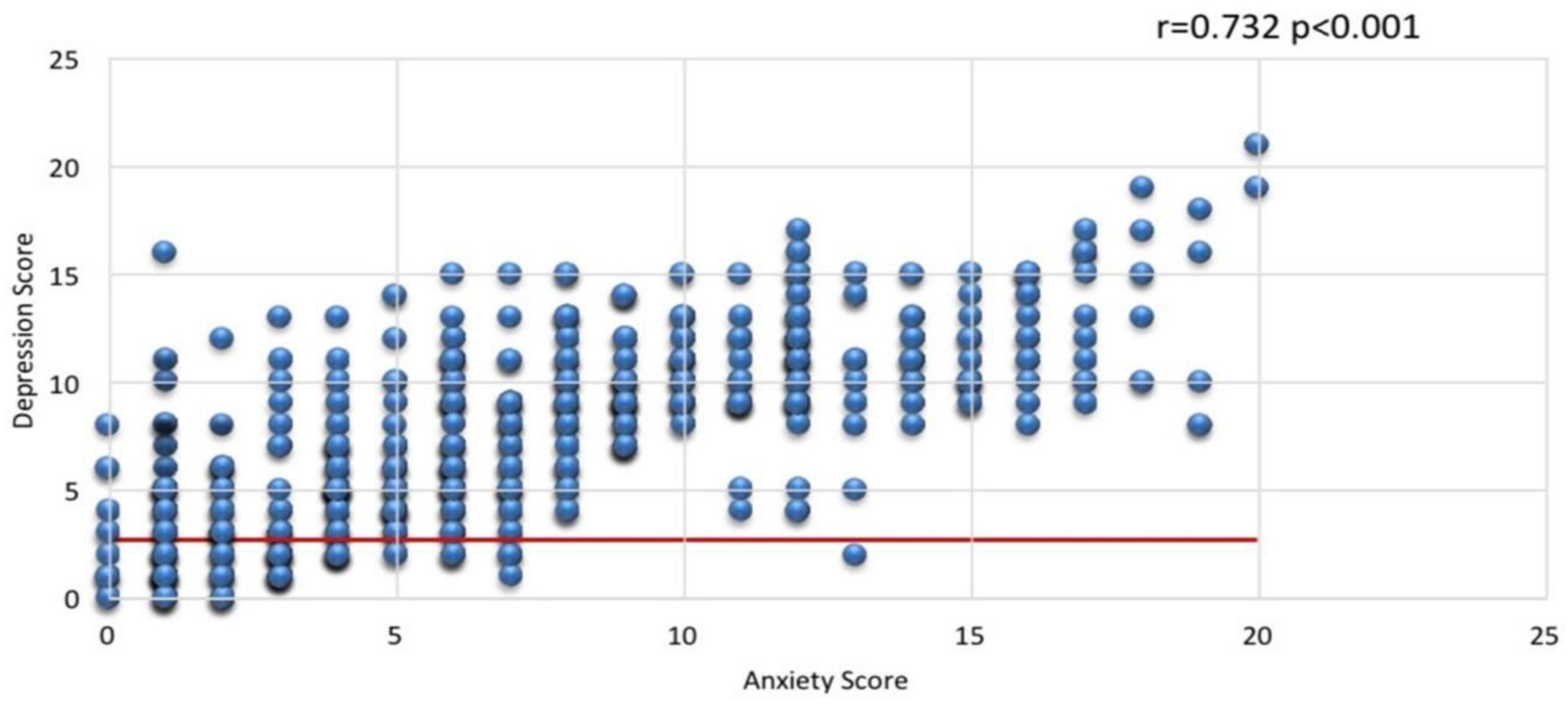

Figure 2 Shows the correlation between anxiety score and depression score.

of patients, relationships, and daily activities, and increase the incidence of depression and anxiety. ${ }^{14}$ This study was conducted for the assessment of anxiety and depression in patients with acne as compared with controls matched for age and sex. In this study, the prevalence of acne significantly differed according to marital status, in contrast to the studies of Alanazi et al ${ }^{15}$ and Öztekin, ${ }^{16}$ which showed that the prevalence of acne was not significantly affected by marital status. However, many studies showed that the use of contraception and menstrual disorders were significant risk factors of acne. ${ }^{17}$ Others advocate that the difference in the prevalence of acne between males and females is related to the onset of puberty. ${ }^{18}$ On the other hand, Ali et $\mathrm{al}^{19}$ found that marriage is a protective factor against acne, which is consistent with this study finding. The influence of marital status on the incidence of acne has not been fully elucidated yet, with considerable ambiguity. Nevertheless, few researchers believe that marriage has a pleasant impact on acne vulgaris, ${ }^{20,21}$ which is attributed to a normal sexual activity and in turn elicits a desirable overall impact on individuals. ${ }^{21-23}$ This rationale is clearly not well grounded. On other hand, decreased sexual activity was associated with the development of acne. ${ }^{24}$

Of the total number of patients with acne vulgaris, $62.5 \%$ had a moderate form of acne, and the rest of patients were equally distributed between the mild and severe acne groups (18\%). This result corresponds to the report of Kurtalić et $\mathrm{al}^{25}$ that most respondents $(80 \%)$ were diagnosed as having a moderate form of acne.
In this study, the anxiety and depression levels were evaluated using the HADS. The overall anxiety score was higher in the case group than in the control group, with a significant difference $(\mathrm{p}=0.031)$. The depression score was higher in the acne group than in the control group but not significantly. This agrees with the finding of Golchai ${ }^{26}$ that the overall anxiety score showed a significant difference between the acne and control groups in their study $(\mathrm{p}<0.001)$ and depression score showed no significant difference. Dalgard et $\mathrm{al}^{27}$ found that patients with common skin diseases were associated with high prevalence rates of anxiety disorders, depression, and suicidal ideations as compared with the control group $(17.2 \%$ vs $11.1 \%, 10.1 \%$ vs $4.3 \%$, and 12.7 vs $8.3 \%$, respectively). In the acne group, no significant association was found between the severity of acne and anxiety and depression, indicating that we cannot take the clinical features of acne as a predicator of the psychological status of patients. ${ }^{25}$ However, other studies showed that depression is an important indicator of the disease and showed a high prevalence in comparison with the control group. ${ }^{16}$ Some reports also suggested that acne severity worsened the psychological status of patients, mainly those with depression. ${ }^{28}$ Jena and Sahoo ${ }^{10}$ revealed a high association of acne vulgaris with depression and anxiety scores, but was no relationship with acne severity. Mishra et $\mathrm{al}^{29}$ showed a significant correlation between the depression score and acne severity, as these patients were more affected with their external appearance and lesion severity. 
Table 3 Statistical Association Between Anxiety Level and Sociodemographic Characteristics Between the Patients with and Those Without Acne Vulgaris $(n=592)$

\begin{tabular}{|c|c|c|c|c|}
\hline \multirow[t]{2}{*}{ Factor } & \multicolumn{2}{|l|}{ Case } & \multicolumn{2}{|l|}{ Control } \\
\hline & $\begin{array}{l}\text { Anxious } n(\%) \\
(n=140)\end{array}$ & $\begin{array}{l}\text { Not Anxious n (\%) } \\
(n=156)\end{array}$ & $\begin{array}{l}\text { Anxious } n(\%) \\
(n=119)\end{array}$ & $\begin{array}{l}\text { Not Anxious } n(\%) \\
(n=177)\end{array}$ \\
\hline $\begin{array}{l}\text { Sex } \\
\text { - Male } \\
\text { - Female }\end{array}$ & $\begin{array}{l}36(25.7 \%) \\
104(74.3 \%)\end{array}$ & $\begin{array}{l}60(38.5 \%) \\
96(61.5 \%)\end{array}$ & $\begin{array}{l}35(29.4 \%) \\
84(70.6 \%)\end{array}$ & $\begin{array}{l}61(34.5 \%) \\
116(65.5 \%)\end{array}$ \\
\hline$P$-value ${ }^{\S}$ & \multicolumn{2}{|l|}{$0.019 * *$} & \multicolumn{2}{|l|}{0.363} \\
\hline $\begin{array}{l}\text { Age group } \\
\begin{array}{l}\text { - } 12-22 \text { years } \\
\text { - } 23-33 \text { years } \\
\text { - } 34-60 \text { years }\end{array}\end{array}$ & $\begin{array}{l}57(40.7 \%) \\
55(39.3 \%) \\
28(20.0 \%)\end{array}$ & $\begin{array}{l}53(34.0 \%) \\
72(46.2 \%) \\
31(19.9 \%)\end{array}$ & $\begin{array}{l}48(40.3 \%) \\
51(42.9 \%) \\
20(16.8 \%)\end{array}$ & $\begin{array}{l}63(35.6 \%) \\
74(41.8 \%) \\
40(22.6 \%)\end{array}$ \\
\hline$P$-value ${ }^{\mathcal{S}}$ & \multicolumn{2}{|l|}{0.424} & \multicolumn{2}{|l|}{0.444} \\
\hline $\begin{array}{l}\text { Nationality } \\
\text { - Saudi } \\
\text { - Non-Saudi }\end{array}$ & $\begin{array}{l}137(97.9 \%) \\
03(02.1 \%)\end{array}$ & $\begin{array}{l}148(94.9 \%) \\
08(05.1 \%)\end{array}$ & $\begin{array}{l}115 \text { (96.6\%) } \\
04 \text { (03.4\%) }\end{array}$ & $\begin{array}{l}164(92.7 \%) \\
13(07.3 \%)\end{array}$ \\
\hline$P$-value ${ }^{\S}$ & \multicolumn{2}{|l|}{0.175} & \multicolumn{2}{|l|}{0.149} \\
\hline $\begin{array}{l}\text { Marital status } \\
\text { - Never married } \\
\text { - Married }\end{array}$ & $\begin{array}{l}98(70.0 \%) \\
42(30.0 \%)\end{array}$ & $\begin{array}{l}113(72.4 \%) \\
43(27.6 \%)\end{array}$ & $\begin{array}{l}73(61.3 \%) \\
46(38.7 \%)\end{array}$ & $\begin{array}{l}90(50.8 \%) \\
87(49.2 \%)\end{array}$ \\
\hline$P$-value ${ }^{\S}$ & \multicolumn{2}{|l|}{0.644} & \multicolumn{2}{|l|}{0.075} \\
\hline $\begin{array}{l}\text { Educational level } \\
\text { - High school or lower } \\
\text { - Bachelor's degree }\end{array}$ & $\begin{array}{l}36(25.7 \%) \\
104(74.3 \%)\end{array}$ & $\begin{array}{l}53(34.0 \%) \\
103(66.0 \%)\end{array}$ & $\begin{array}{l}27(22.7 \%) \\
92(77.3 \%)\end{array}$ & $\begin{array}{l}44(24.9 \%) \\
133(75.1 \%)\end{array}$ \\
\hline P-value ${ }^{\S}$ & \multicolumn{2}{|l|}{0.122} & \multicolumn{2}{|l|}{0.668} \\
\hline
\end{tabular}

Notes: ${ }^{\S} \mathrm{P}$-value calculated using the chi-square test. $* *$ Significant at $\mathrm{p}<0.05$.

In this study, we found a significant difference in anxiety level between the sexes in the acne group. However, depression was not affected by sex, while Kurtalić et al ${ }^{25}$ showed that both anxiety and depression level were not affected by sex. Other studies showed significant differences in depression and anxiety scores according to age based on the strong association between adolescence and the occurrence of depression and anxiety, referred to as a liability of this age group to emotional disturbances, and found decreases in the frequency of depression and anxiety with the progression of age. ${ }^{7}$ A significant relationship was found between the depression scale score and educational level in the control group. Mental health outcome is remarkably influenced by educational level. ${ }^{30,31}$ Evidently, a wide body of research indicates that the higher the educational level, the less likely an individual will develop depressive symptoms, imposing a beneficial protective influence of educational attainment against depression, whereas under- education might negatively impact mental well-being, placing individuals at high risk of depression. ${ }^{31,32}$ Alternatively, other authors advocate that higher educational attainment is inversely related to mental status, which in turn is in accordance with this study finding. This can be explained by the expansion of education with discrepancy in educational level and occupation. ${ }^{30}$ In addition, the goal of educational attainment with the desired benefits from the rewards given according to educational degrees earned will have consequences on personal life, family, and well-being. ${ }^{33-35}$

In this study, we used the HADS in both the screening and diagnosis of anxiety and depression. We did not include other factors that might have direct psychosocial effects on the patients with acne, including those receiving psychiatric treatments, therapeutic management, and non-therapeutics such as nutritional supplementation. 
Table 4 Statistical Association Between Depression Level and the Sociodemographic Characteristics of the Patient with and Those Without Acne Vulgaris $(n=592)$

\begin{tabular}{|c|c|c|c|c|}
\hline \multirow[t]{2}{*}{ Factor } & \multicolumn{2}{|l|}{ Case } & \multicolumn{2}{|l|}{ Control } \\
\hline & $\begin{array}{l}\text { Depressed n (\%) } \\
(n=152)\end{array}$ & $\begin{array}{l}\text { Not Depressed n (\%) } \\
(n=144)\end{array}$ & $\begin{array}{l}\text { Depressed n (\%) } \\
(n=150)\end{array}$ & $\begin{array}{l}\text { Not Depressed n (\%) } \\
(n=146)\end{array}$ \\
\hline \multicolumn{5}{|l|}{ Sex } \\
\hline - Male & $43(28.3 \%)$ & 53 (36.8\%) & 55 (36.7\%) & $4 \mathrm{I}(28.1 \%)$ \\
\hline - Female & 109 (71.7\%) & 91 (63.2\%) & 95 (63.3\%) & 105 (7I.9\%) \\
\hline P-value ${ }^{\S}$ & \multicolumn{2}{|l|}{0.118} & \multicolumn{2}{|l|}{0.115} \\
\hline \multicolumn{5}{|l|}{ Age group } \\
\hline - $12-22$ years & 55 (36.2\%) & 55 (38.2\%) & 53 (35.3\%) & 58 (39.7\%) \\
\hline - 23-33* years & 63 (4I.4\%) & 64 (44.4\%) & 62 (4I.3\%) & $63(43.2 \%)$ \\
\hline - 34-60 years & 34 (22.4\%) & 25 (17.4\%) & 35 (23.3\%) & 25 (17.1\%) \\
\hline P-value ${ }^{\S}$ & \multicolumn{2}{|l|}{0.558} & \multicolumn{2}{|l|}{0.397} \\
\hline \multicolumn{5}{|l|}{ Nationality } \\
\hline - Saudi & 147 (96.7\%) & 138 (95.8\%) & 142 (94.7\%) & 137 (93.8\%) \\
\hline - Non-Saudi & 05 (03.3\%) & 06 (04.2\%) & 08 (05.3\%) & 09 (06.2\%) \\
\hline$P$-value ${ }^{\S}$ & \multicolumn{2}{|l|}{0.690} & \multicolumn{2}{|l|}{0.759} \\
\hline \multirow{3}{*}{$\begin{array}{l}\text { Marital status } \\
\text { - Never married } \\
\text { - Married }\end{array}$} & & & & \\
\hline & $105(69.1 \%)$ & $106(73.6 \%)$ & 83 (55.3\%) & $80(54.8 \%)$ \\
\hline & 47 (30.9\%) & 38 (26.4\%) & 67 (44.7\%) & $66(45.2 \%)$ \\
\hline$P$-value ${ }^{\S}$ & \multicolumn{2}{|l|}{0.389} & \multicolumn{2}{|l|}{0.926} \\
\hline \multirow{3}{*}{$\begin{array}{l}\text { Educational level } \\
\text { - High school or lower } \\
\text { - Bachelor's degree }\end{array}$} & & & & \\
\hline & $40(26.3 \%)$ & 49 (34.0\%) & 27 (18.0\%) & $44(30.1 \%)$ \\
\hline & II (73.7\%) & 95 (66.0\%) & $123(82.0 \%)$ & 102 (69.9\%) \\
\hline$P$-value ${ }^{\S}$ & \multicolumn{2}{|l|}{0.148} & \multicolumn{2}{|l|}{$0.014 * *$} \\
\hline
\end{tabular}

Notes: ${ }^{\S} \mathrm{P}$-value calculated using the chi-square test. $*$ Significant at $\mathrm{p}<0.05$.

Table 5 Relationship Between Acne Severity and the Anxiety and Depression Scores of the Patients with Acne Vulgaris ( $\mathrm{n}=296$ )

\begin{tabular}{|l|l|l|l|l|}
\hline \multirow{2}{*}{ Severity of Acne } & Acne Group & & & \\
\cline { 2 - 5 } & Anxiety Median (n= 296) & F-test; P-value $\$$ & Depression Median (n = 296) & F-test; P-value $\$$ \\
\hline Mild & $7(4-10)$ & P-0.138 & $5(3-10)$ & P-0.175 \\
Moderate & $6.5(3.75-11)$ & & $5(3-8)$ & \\
Severe & $9(5-13)$ & & $7(4-10)$ & \\
\hline
\end{tabular}

Note: ${ }^{\S}$-value calculated using the Kruskal-Wallis test.

\section{Conclusion}

A positive correlation was found between anxiety and depression scores in the patients with acne, which was not related to age group or educational level. However, the anxiety scores of the patients with acne showed a significant relationship with sex. In the management of acne vulgaris, long-term psychometric assessment is essential.

\section{Strength and Limitations}

The main strength of the study lies in the fact that it was based on a large sample size, was not restricted to a specific geographical area or facility, and included adolescents and adults, without restriction to a specific age group. In terms of limitations, some demographic variables were not matched between the cases and controls. Furthermore, some of our controls were selected from 
among employees of hospitals, including physicians and nurses, and might have higher levels of health in comparison with the general population.

\section{Abbreviations}

GAGS, Global Acne Grading System; HADS, Hospital Anxiety and Depression Scale; SPSS, Statistical Package for Social Sciences.

\section{Author Contributions}

All authors made substantial contributions to conception and design, acquisition of data, or analysis and interpretation of data; took part in drafting the article or revising it critically for important intellectual content; agreed to submit to the current journal; gave final approval of the version to be published; and agree to be accountable for all aspects of the work.

\section{Funding}

The authors received no financial support for the research, authorship, and/or publication of this article.

\section{Disclosure}

The authors declare that there are no conflicts of interest.

\section{References}

1. Yan HM, Zhao HJ, Guo DY, Zhu PQ, Zhang CL, Jiang W. Gut microbiota alterations in moderate to severe acne vulgaris patients. J Dermatol. 2018;45(10):1166-1171. doi:10.1111/1346-8138.14586

2. Bhate K, Williams HC. Epidemiology of acne vulgaris. Br J Dermatol. 2013;168(3):474-485. doi:10.1111/bjd.12149

3. Tan AU, Schlosser BJ, Paller AS. A review of diagnosis and treatment of acne in adult female patients. Int J Womens Dermatol. 2018;4 (2):56-71.

4. Shakoor A, Shaheen JA, Khan JI. Association of anxiety and depression with acne: evaluation of pathoplastic effect of adolescence on this comorbidity. J Pak Assoc Dermatol. 2012;22(4):336-341.

5. Haxby JV, Hoffman EA, Gobbini MI. The distributed human neural system for face perception. Trends Cogn Sci. 2000;4(6):223-233. doi:10.1016/S1364-6613(00)01482-0

6. Samreen S, Siddiqui NA, Mothana RA. Prevalence of anxiety and associated factors among pharmacy students in Saudi Arabia: a cross-sectional study. BioMed Res Int. 2020;2020:2436538. doi: $10.1155 / 2020 / 2436538$

7. Mleeh NT, Alshamrani HM, Basyouni RN, Alshehri KA, Algethami MR, Sehlo MG. Prevalence and predictors of depression among dermatology clinic patients in a teaching hospital, Jeddah, Saudi Arabia. J Fam Med Prim Care. 2019;8(7):2496-2501. doi:10.4103/jfmpc.jfmpc_399_19

8. Samuels DV, Rosenthal R, Lin R, Chaudhari S, Natsuaki MN. Acne vulgaris and risk of depression and anxiety: a meta-analytic review. $J$ Am Acad Dermatol. 2020;83(2):532-541. doi:10.1016/j. jaad.2020.02.040
9. Hazarika N, Archana M. The psychosocial impact of acne vulgaris. Indian $J$ Dermatol. 2016;61(5):515-520. doi:10.4103/00195154.190102

10. Jena AK, Sahoo S. Evaluation of associated anxiety and depression in patients with acne vulgaris: a hospital based Clinico-Epidemiological Study. Paripex Indian J Res. 2016;10(5):82-83.

11. Doshi A, Zaheer A, Stiller MJ. A comparison of current acne grading systems and proposal of a novel system. Int J Dermatol. 1997;36 (6):416-418. doi:10.1046/j.1365-4362.1997.00099.x

12. Zigmond AS, Snaith RP. The hospital anxiety and depression scale. Acta Psychiatr Scand. 1983;67(6):361-370. doi:10.1111/j.16000447.1983.tb09716.x

13. Terkawi AS, Tsang S, AlKahtani GJ, et al. Development and validation of Arabic version of the Hospital Anxiety and Depression Scale. Saudi J Anaesth. 2017;11(Suppl 1):S11-S18. doi:10.4103/sja. SJA 4317

14. Onderdijk AJ, Van der Zee HH, Esmann S, et al. Depression in patients with hidradenitis suppurativa. J Eur Acad Dermatol Venereol. 2013;27 (4):473-478. doi:10.1111/j.1468-3083.2012.04468.x

15. Alanazi MS, Hammad SM, Mohamed AE. Prevalence and psychological impact of acne vulgaris among female secondary school students in Arar city, Saudi Arabia, in 2018. Electron Phys. 2018;10 (8):7224-7229. doi:10.19082/7224

16. Öztekin C, Öztekin A. The association of depression, loneliness and internet addiction levels in patients with acne vulgaris. BioPsychoSocial Med. 2020;14(1):17. doi:10.1186/s13030-02000190-y

17. Di Landro A, Cazzaniga S, Cusano F, et al. Adult female acne and associated risk factors: results of a multicenter case-control study in Italy. J Am Acad Dermatol. 2016;75(6):1134-1141.e1. doi:10.1016/j. jaad.2016.06.060

18. Heng AHS, Chew FT. Systematic review of the epidemiology of acne vulgaris. Sci Rep. 2020;10(1):5754. doi:10.1038/s41598-020-62715-3

19. Ali F. Determination of various risk factors associated with acne vulgaris infection in Quetta, Pakistan. Pure Appl Biol. 2014;8(3):47.

20. van Studdiford HT. The effects of hormones of sex glands on acne. Arch Derm Syphilol. 1935;3(1):333. doi:10.1001/ archderm.1935.01460210044005

21. Strickler A. Etiological factors in acne vulgaris. Am J Med Sci. 1917;154:579. doi:10.1097/00000441-191710000-00012

22. Riley ID. Testosterone propionate in acne vulgaris. $\mathrm{Br} J$ Derm Syphilol. 1939;51:119. doi:10.1111/j.1365-2133.1939.tb10659.x

23. Goodman G. Acne - natural history, facts and myths. Aust Fam Phys. 2006;35:613-616.

24. Misery L, Wolkenstein P, Amici JM, et al. Consequences of acne on stress, fatigue, sleep disorders and sexual activity: a population-based study. Acta Derm Venereol. 2015;95:485-488. doi:10.2340/00015555-1998

25. Kurtalić N, Hadžigrahić N, Tahirović H, Šadić S. Assessment of anxiety and depression in adolescents with acne vulgaris related to the severity of clinical features and gender. Acta Med Acad. 2010;39(2):159-164.

26. Golchai J, Khani SH, Heidarzadeh A, Eshkevari SS, Alizade N, Eftekhari H. Comparison of anxiety and depression in patients with acne vulgaris and healthy individuals. Indian J Dermatol. 2010;55 (4):352-354. doi:10.4103/0019-5154.74539

27. Dalgard FJ, Gieler U, Tomas-Aragones L, et al. The psychological burden of skin diseases: a cross-sectional multicenter study among dermatological out-patients in 13 European countries. J Invest Dermatol. 2015;135(4):984-991. doi:10.1038/jid.2014.530

28. Berry S. An assessment of acne, stress, and psychological symptoms in college students: a daily diary study (2020); 2020. Honors Theses. 1371. Available from: https://egrove.olemiss.edu/hon_thesis/1371. Accessed September 20, 2020.

29. Mishra N, Rastogi M, Gahalaut P, Srivastava N, Aggarwal A. Assessment of depression in patients of acne vulgaris and its correlation with severity of acne, post acne scarring and gender. $J$ Pakistan Assoc Dermatol. 2018;27:313-319. 
30. Bracke P, Pattyn E, von Dem Knesebeck O. Overeducation and depressive symptoms: diminishing mental health returns to education. Soc Health Illn. 2013;35(8):1242-1259. doi:10.1111/ 1467-9566.12039

31. Bjelland I, Krokstad S, Mykletun A, Dahl AA, Tell GS, Tambs K. Does a higher educational level protect against anxiety and depression? The HUNT study. Soc Sci Med. 2008;66(6):1334-1345. doi:10.1016/j.socscimed.2007.12.019

32. Lorant V, Deliège D, Eaton W, Robert A, Philippot P, Ansseau M. Socioeconomic inequalities in depression: a meta-analysis. $\mathrm{Am}$ J Epidemiol. 2003;157(2):98-112. doi:10.1093/aje/kwf182
33. Vaisey S. Education and its discontents: overqualification in America, 1972-2002. Soc Forces. 2006;85:835-864. doi:10.1353/sof.2007.0028

34. Verhaest D, Omey E. Objective over-education and worker well-being: a shadow price approach. J Econ Psychol. 2009;30 (3):469-481. doi:10.1016/j.joep.2008.06.003

35. Omary A. National prevalence rates of suicidal ideation and suicide attempts among adults with and without depression. J Nerv Ment Dis. 2021;209(5):378-385. doi:10.1097/NMD.0000000000001309

\section{Publish your work in this journal}

Clinical, Cosmetic and Investigational Dermatology is an international, peer-reviewed, open access, online journal that focuses on the latest clinical and experimental research in all aspects of skin disease and cosmetic interventions. This journal is indexed on CAS.
The manuscript management system is completely online and includes a very quick and fair peer-review system, which is all easy to use. Visit http://www.dovepress.com/testimonials.php to read real quotes from published authors. 